\title{
DESIGNING OF NANOCOMPOSITE MODEL STRUCTURE USING GLYCITEIN AND GENISTEIN WITH TWELVE DIFFERENT METAL ATOMS USING IN SILICO METHOD
}

\author{
Doyel Chatterjee ${ }^{1}$, Sukanya Basu Mallick ${ }^{1}$, Debraj Hazra ${ }^{1}$, Rajat Pal ${ }^{1} ه$ \\ ${ }^{1}$ Department of Microbiology and Biotechnology, Sister Nivedita University, DG 1/ 2, Action Area-I, Kolkata- \\ 700156, West Bengal, India.
}

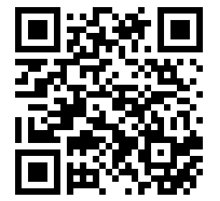

Received 05 October 2021

Accepted 20 October 2021

Published 30 November 2021

CorrespondingAuthor

Rajat Pal, rajat.p@snuniv.ac.in

DOI 10.29121/ijetmr.v8.i11.2021.1058

Funding: This research received no specific grant from any funding agency in the public, commercial, or not-for-profit sectors.

Copyright: (C) 2021 The Author(s). This is an open access article distributed under the terms of the Creative Commons Attribution License, which permits unrestricted use, distribution, and reproduction in any medium, provided the original author and source are credited.

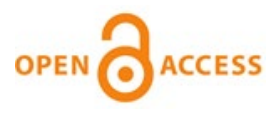

\section{ABSTRACT}

Nanocomposite formulation is still in its evolving state. However due to its significant therapeutic applications it has grabbed the attention of many researchers. Isoflavonewhich is widely found in soy products have tremendous medicinal propertieswhen it interacts with nanoparticles can become a boon. Hence in this study, we are reporting the interaction properties/patterns of two ubiquitous flavones namelyGlycitein and Genistein forming a nanocomposite model with 12 different metals such as Gold, Silver, Palladium, Platinum, Ruthenium, Rhodium, Cadmium, Iron, Nickel, Zinc, Copper and Antimony based ontheir potency to form nanoparticles. To mimic the Nanocomposite, model the formulation was conducted in Avogadro Software for windows. Glycitein and Genistein create a possibility of selecting the most suitable $-\mathrm{OH}$ position that would serve as the binding site. On selection of the appropriate binding site the interaction amid two molecules of glycitein and genistein placed sidewise held together by above-mentioned metals also surrounded by the same metal on another vacant $-\mathrm{OH}$ position forming a close saturated structure subjected for interaction. Based on predominantly energy levels the least energy obtained model was Cadmium and the peak procured by Antimony making it least stable and unfavorable for the perceived result.

Keywords: Isoflavone, Nanoparticle, Glycitein, Genistein, and Avogadro software

\section{INTRODUTION}

Over the years, science and technology have opened wide doors for various new subjects. In this regard research is one such pillar that has forced people to look beyond the decision boundaries. One such subject that is evolving is nanoparticle technology. Though it appears to be tiny, it can play a pivotal role in tending various medical applications. In this context scientists after arranging their fundamentals had led to findings of Nanoparticle mediated drug delivery. Nanoparticles are defined as solid particles with sizes ranging from $10 \mathrm{~nm}-100 \mathrm{~nm}$. They are basically two types of nanoparticles [Jong and Borm (2008)]; polymeric [Crucho and Barros (2017)], that entrap drug molecules inside their core [Vrignaud et al. (2011)] and metallic [Venkatesh et al. (2018)], that attach the drug molecule directly on the surface [Levin et al. (2009)]. Although our focus stays on the latter one as it seems to be a more oriented one towards recovering from various ailments. The metals selected here are based on their potency to form nanocomposite structures and also used in therapeutic applications namely

\footnotetext{
How to cite this article (APA): Chatterjee, D., Mallick, S. B., Hazra, D., and Pal, R. (2021). Designing of Nanocomposite model structure using Glycitein and Genistein with twelve different metal atoms using in silico method. International Journal of Engineering Technologies and Management Research, 8(11), 14-22. doi: 10.29121/ijetmr.v8.i11.2021.1058
} 
gold (Au) [Duncan et al. (2010)],silver (Ag) [Dos Santos et al. (2014)], palladium (Pd) [Adams et al. (2014)], platinum (Pt) [Kim et al. (2010)], ruthenium (Ru) [Viauet al. (2003)], rhodium (Rh) [Xu et al. (2019)], cadmium (Cd) [Qi et al. (2001)], iron (Fe) [Mahdy et al. (2012)], nickel (Ni) [ Guo et al. (2009)], zinc (Zn) [Rojas et al. (2016)], copper (Cu) [Kruk et al. (2015)], and antimony (Sb) [Yin et al. (2019)].

Isoflavone - polyphenolic compounds naturally occurring can predominantly be found in various food supplements exemplary in soy products and legumes [ Thrane et al. (2017)]. They can be a helping aid in treating various serious conditions like type II diabetes mellitus [Pabich and Materska (2019)], cardiovascular diseases [Thangavel et al. (2019)], cholesterol-reducing [Lu et al. (2019)], or in chemotherapeutics [Spagnuolo et al. (2015)] and used as strong antioxidants [Shimoda and Hamada (2010)]. The isoflavone being phytoestrogen also plays an effective role in alleviating women's menstrual problems [Thangavel et al. (2019)]. Based on all this groundwork's we select Glycitein, as one of the active components of soy products exhibiting exceptional results in biological and estrogenic activity mainly due to its chemical forms in which it exists [Vitale et al. (2013)] and also Genistein which is used as an angiogenesis inhibitor [Suet al. (2005)]. Hence, the isoflavone glycitein and genistein can become a prime source to study its interactions in association with the above-mentioned 12 metals.

\section{MATERIALS AND METHODS:}

Since a nanoparticle consists of several metal atoms when synthesized.Hence, for the representation of the same, we consider a single metal atom for its interaction with the isoflavone.To study the inter-relationship amid the considered isoflavone and the metal atom, both glycitein and genistein structures constructed in the Avogadro software [Hanwell et al. (2012)] were subjected to energy optimization. Glycitein has 2 - $\mathrm{OH}$ groups present at the 7 and 4' position whereas genistein has $3-\mathrm{OH}$ groups at the $4^{\prime}, 5$, and 7position respectively. To ensure the susceptible position where energy-optimization could be the least.So, metal atoms were added in their respective binding sites and the least one was to be selected. The 12 metals were selected in terms of their capability to form nanocomposite structures and also their applications in therapeutics, those are namely; gold $(\mathrm{Au})$ [Duncan et al. (2010)],silver (Ag) [Dos Santos et al. (2014)], palladium (Pd) [Adams et al. (2014)], platinum (Pt) [Kim et al. (2010)], ruthenium (Ru) [Viauet al. (2003)], rhodium (Rh) [Xu et al. (2019)], cadmium (Cd) [Qi et al. (2001)], iron (Fe) [Mahdy et al. (2012)], nickel (Ni) [ Guo et al. (2009)], zinc (Zn) [Rojas et al. (2016)], copper (Cu) [Kruk et al. (2015)], and antimony (Sb) [Yin et al. (2019)]. The 4' OH of glycitein and $5 \mathrm{OH}$ of genistein were observed to be the most suitable ones. Therefore, the $\mathrm{OH}$ groups present at the 4' and 5 positions were replaced by a metal atom one at a time. In this study, we are trying to report two of the same drug molecules interacting with the metal atom. Precisely, a metal settled in between with a glycitein or genistein molecule situated sidewisealong with the same metal being placed at other $\mathrm{OH}$ positions. On that account, the entire setup could be metals attached altogether to provide a circumference for the drug interaction. On completion of the entire build up the energy optimization was monitored along with the bond angle and bond length $\left(\mathrm{O}_{\mathrm{R}}-\right.$ Metal- $\left.\mathrm{O}_{\mathrm{L}}\right)$ were reported below. 


\section{RESULTS AND DISCUSSION}

\section{Interaction of Glycitein with a metal nanoparticle}

The structure of Glycitein was made using Avogadro software as shown in Figure 1 with its chemical structure, where the energy was found to be 244.853 $\mathrm{KJ} / \mathrm{Mol}$. The molecule consists of three benzene rings associated with 2 - $\mathrm{OH}$ groups serving as metal binding sites, present at the 7ortho position of A ring (Figure $2 \mathrm{~A}$ ) and 4' meta position of B ring (Figure 2B). To be noted, that single drug molecule of glycitein when - $\mathrm{OH}$ wasreplaced at the 7 positions and the energy was found to be $241.785 \mathrm{KJ} / \mathrm{Mol}$ after energy optimization it was found to be little less in comparison with the 4 ' binding site that is $242.785 \mathrm{KJ} / \mathrm{Mol}$.

A)<smiles>COc1cc2c(=O)c(-c3ccc(O)cc3)coc2cc1O</smiles>

B)

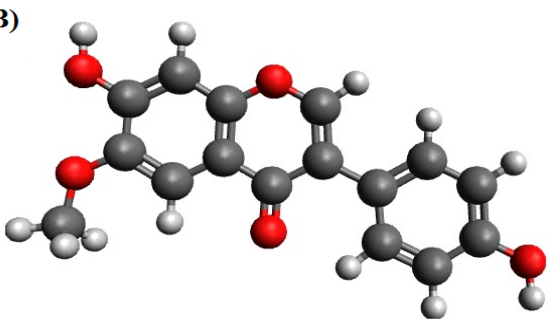

Figure 1 A) Chemical structure of glycitein, B) Structure of glycitein formulated using Avogadro software

A)

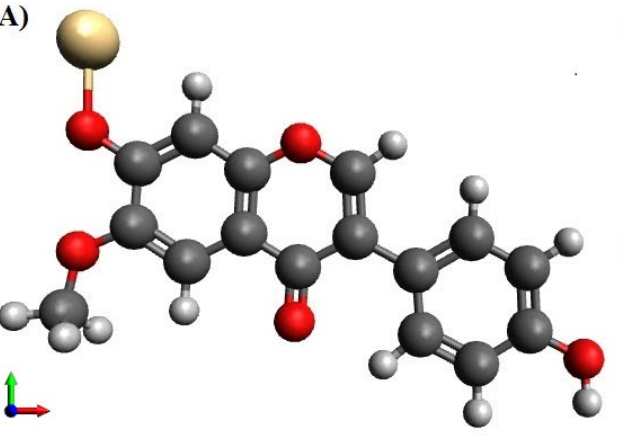

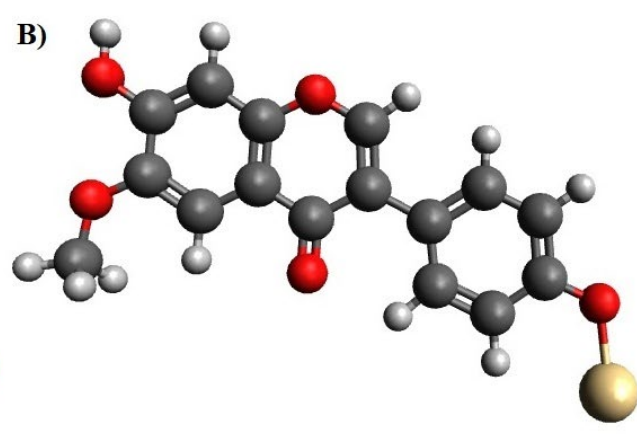

Figure 2 Structure of Glycitein molecule with metal at - $\mathrm{OH}$ position A) Cd metal at $7 \mathrm{OH}$ position, B) Cd metal at 4' $\mathrm{OH}$ position

But, when the interaction took place amid 2 glycitein molecules and a metal atom is forming the bridge, surprisingly the 4' site was found to be more susceptible than 7 position. For instance, the energy level for cadmium at 4'OH was 461.132 $\mathrm{KJ} / \mathrm{Mol}$ and at the $7 \mathrm{OH}$ position it was found to be $463.43 \mathrm{KJ} / \mathrm{Mol}$.One of the reasons for the selection of cadmium metal in order to find the most suitable binding site is due to the previous studies conducted in the same software where we found cadmium gives the least energy after optimization against other metals [27]. Once sure of the destined position then, the drug molecules together bonded with the above-mentioned metal atoms at the 4' meta-position and were subjected to energy optimization, one followed by the other. While monitoring the energy levels when the central metal atom was holding the two glycitein molecules, followed by the 
addition of twin metal atoms on either 7-position seemed to be decreasing hence it can be said on the addition of metals, the setups energy was minimizing.

On reaching its threshold where the structure was quite stable, the optimized energy of cadmium metal was found to be least about $461.132 \mathrm{KJ} / \mathrm{Mol}$ (Figure $3 \mathrm{G}$ ) with Platinum slightly greater than around $461.222 \mathrm{KJ} / \mathrm{Mol}$ (Figure $3 \mathrm{D}$ ) in comparison to the other 12 metals; On contrary, antimony was at its peak whose energy was when calculated gave a value of $519.92 \mathrm{KJ} / \mathrm{Mol}$ as depicted in Figure 3L. The figures mentioned below can give a wider view followed by (Table 1) stating all the respective molecules: energies, bond angle and bond length.
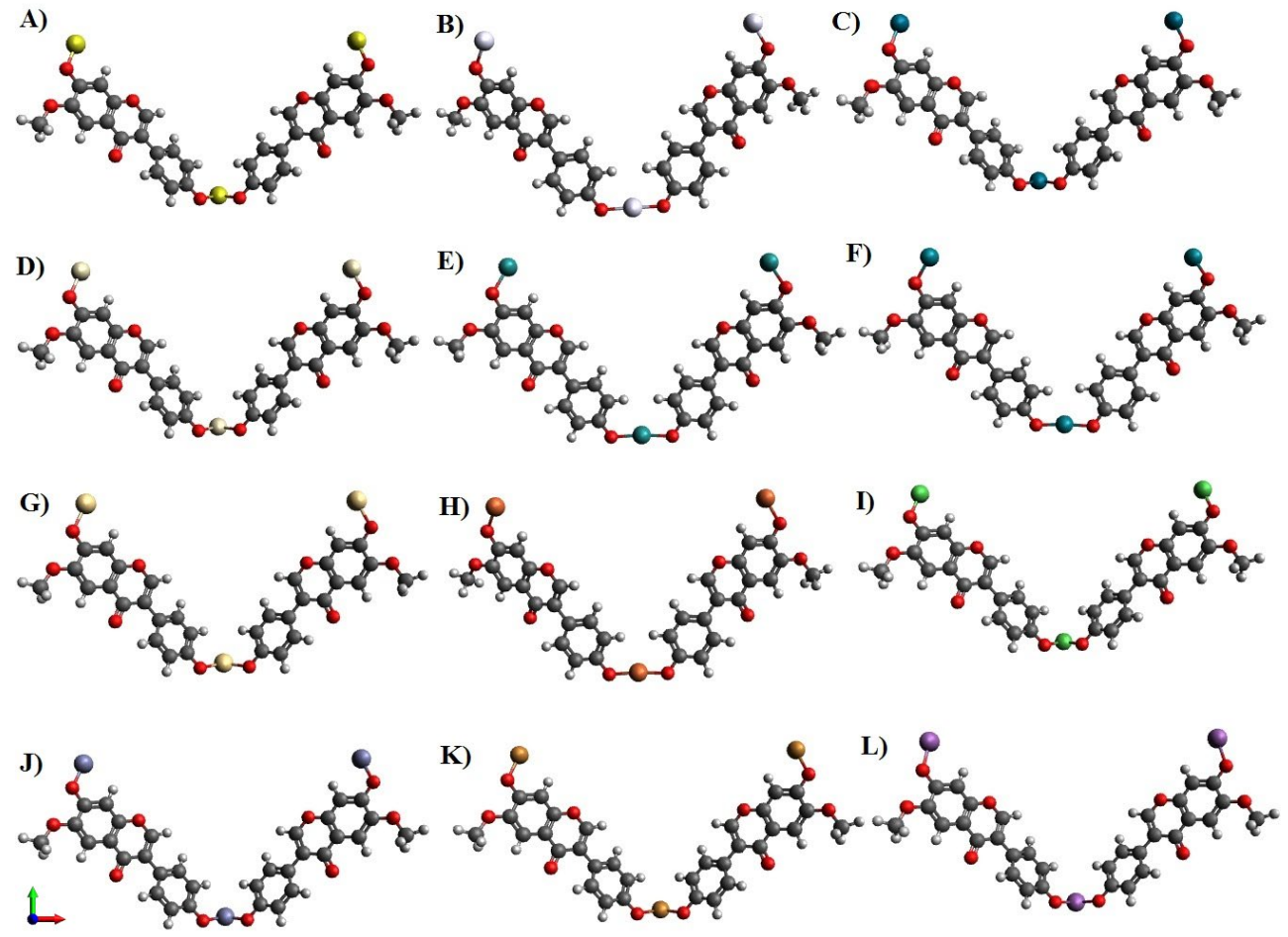

Figure 3 Nanocomposite model structure of glycitein with A) Gold (Au_Gy), B) Silver (Ag_Gy), C) Palladium (Pd_Gy), D) Platinum (Pt_Gy), E) Ruthenium (Ru_Gy), F) Rhodium (Rh_Gy), G) Cadmium (Cd_Gy), H) Iron (Fe_Gy), I) Nickel (Ni_Gy), J) Zinc ( Zn_Gy), K) Copper (Cu_Gy), L) Antimony (Sb_Gy).

Table 1 List of energy levels ( $\mathrm{KJ} / \mathrm{Mol})$ for different metal-glycitein nanocomposites with their bond angles (OL-Metal-OR) and bond lengths (OL-Metal and Metal-OR). Here suffix $L$ and $R$ denotes right and left side.

\begin{tabular}{|c|c|c|c|c|c|}
\hline \multirow[t]{2}{*}{ Metal } & \multirow{2}{*}{$\begin{array}{l}\text { Compound } \\
\text { name }\end{array}$} & \multirow{2}{*}{$\begin{array}{c}\text { Energy } \\
\text { (KJ/Mol) }\end{array}$} & \multirow{2}{*}{\begin{tabular}{c}
\multicolumn{2}{c}{ Bond } \\
Angle \\
$\left.{ }^{\circ}{ }^{\circ}\right)$ \\
OL-Metal-OR $^{2}$
\end{tabular}} & \multicolumn{2}{|c|}{ Bond Length } \\
\hline & & & & $\begin{array}{l}\text { OL-Metal } \\
\text { (§) }\end{array}$ & $\begin{array}{l}\text { Metal-OR } \\
\text { (§) }\end{array}$ \\
\hline Gold & Au_Gy & 467.252 & $89.9^{\circ}$ & $1.859 \AA$ & $1.859 \AA$ \\
\hline Silver & Ag_Gy & 471.191 & $176.0^{\circ}$ & $1.973 \AA$ & $1.973 \AA$ \\
\hline Palladium & Pd_Gy & 462.551 & $89.8^{\circ}$ & $1.914 \AA$ & $1.914 \AA$ \\
\hline Platinum & Pt_Gy & 461.222 & $89.8^{\circ}$ & $1.955 \AA$ & $1.955 \AA$ \\
\hline Ruthenium & Ru_Gy & 468.343 & $174.1^{\circ}$ & $2.018 \AA$ & $2.018 \AA$ \\
\hline Rhodium & Rh_Gy & 470.587 & $175.0^{\circ}$ & $1.896 \AA$ & $1.896 \AA$ \\
\hline
\end{tabular}




$\begin{array}{llllll}\text { Cadmium } & \text { Cd_Gy } & 461.132 & 109.0^{\circ} & 2.000 \AA & 2.000 \AA \\ \text { Iron } & \text { Fe_Gy } & 471.911 & 174.3^{\circ} & 1.891 \AA & 1.891 \AA \\ \text { Nickel } & \text { Ni_Gy } & 463.208 & 90.0^{\circ} & 1.749 \AA & 1.749 \AA \\ \text { Zinc } & \text { Zn_Gy } & 462.135 & 108.9^{\circ} & 1.795 \AA & 1.795 \AA \\ \text { Copper } & \text { Cu_Gy } & 468.417 & 108.7^{\circ} & 1.874 \AA & 1.874 \AA \\ \text { Antimony } & \text { Sb_Gy } & 519.924 & 91.5^{\circ} & 2.014 \AA & 2.014 \AA\end{array}$

\section{Interaction of Genistein with a metal nanoparticle}

Genistein molecule consists of three benzene rings. A structure of Genistein was made with the help of Avogadro software, shown in Figure 4 (A). The energy level was calculated through Avogadro software was then found to be $237.654 \mathrm{KJ} / \mathrm{Mol}$. The molecule has three $\mathrm{OH}$ groups, two of them are present in the A ring and one in the $\mathrm{C}$ ring which serve as positions for binding of metals. In the $\mathrm{A}$ ring, the $\mathrm{OH}$ groups are present at the Para position (5 positions) and Meta position ( 7 positions). In the $\mathrm{C}$ ring, the $-\mathrm{OH}$ group is present at the ortho position (4' position).<smiles>O=c1c(-c2ccc(O)cc2)coc2cc(O)cc(O)c12</smiles>

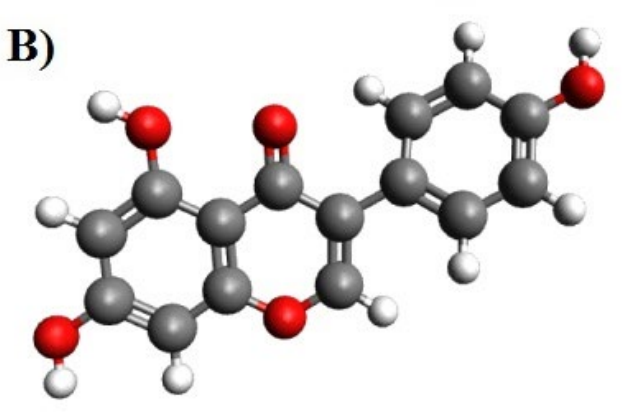

Figure 4 A) Chemical structure of Genistein and B) Structure of Genistein formulated using Avogadro software

The metals selected for this study are widely used to form nanoparticles for applications in therapeutics. The metal atoms were attached to each of the $\mathrm{OH}$ groups of the molecule and the energies at each site were found to be different. Energy of the molecule when interacted with the $\mathrm{OH}$ of the Para position was found to be $232.975 \mathrm{KJ} / \mathrm{Mol}$. Similarly, the energies of the molecule when interacted with the $\mathrm{OH}$ groups at Meta and Ortho position respectively were233.184 KJ/Mol and $233.197 \mathrm{KJ} / \mathrm{Mol}$.
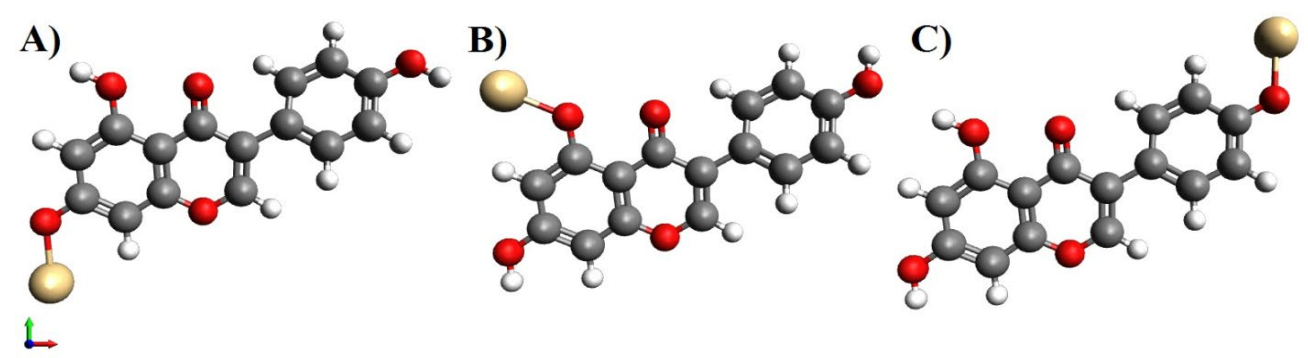

Figure 5 Metal atoms attached at different metal binding sites. 
The $-\mathrm{OH}$ at the Para position (5 position) after being interacted with metal atoms was found to be the most stable site for attaching two drug molecules through a metal atom. Thus, 12 nanocomposite structures were formed when drug molecules interacted with metals. It was also observed that a free Genistein molecule without any metal had more energy. As the metal atoms were being simultaneously added to the drug molecule the energy kept on decreasing. After the complete optimization of energy, the final energy was noted in a table (Table 2). From the table, it can be observed that Genistein, when reacted with Cadmium, had the least energy and had maximum energy when interacting with Antimony.

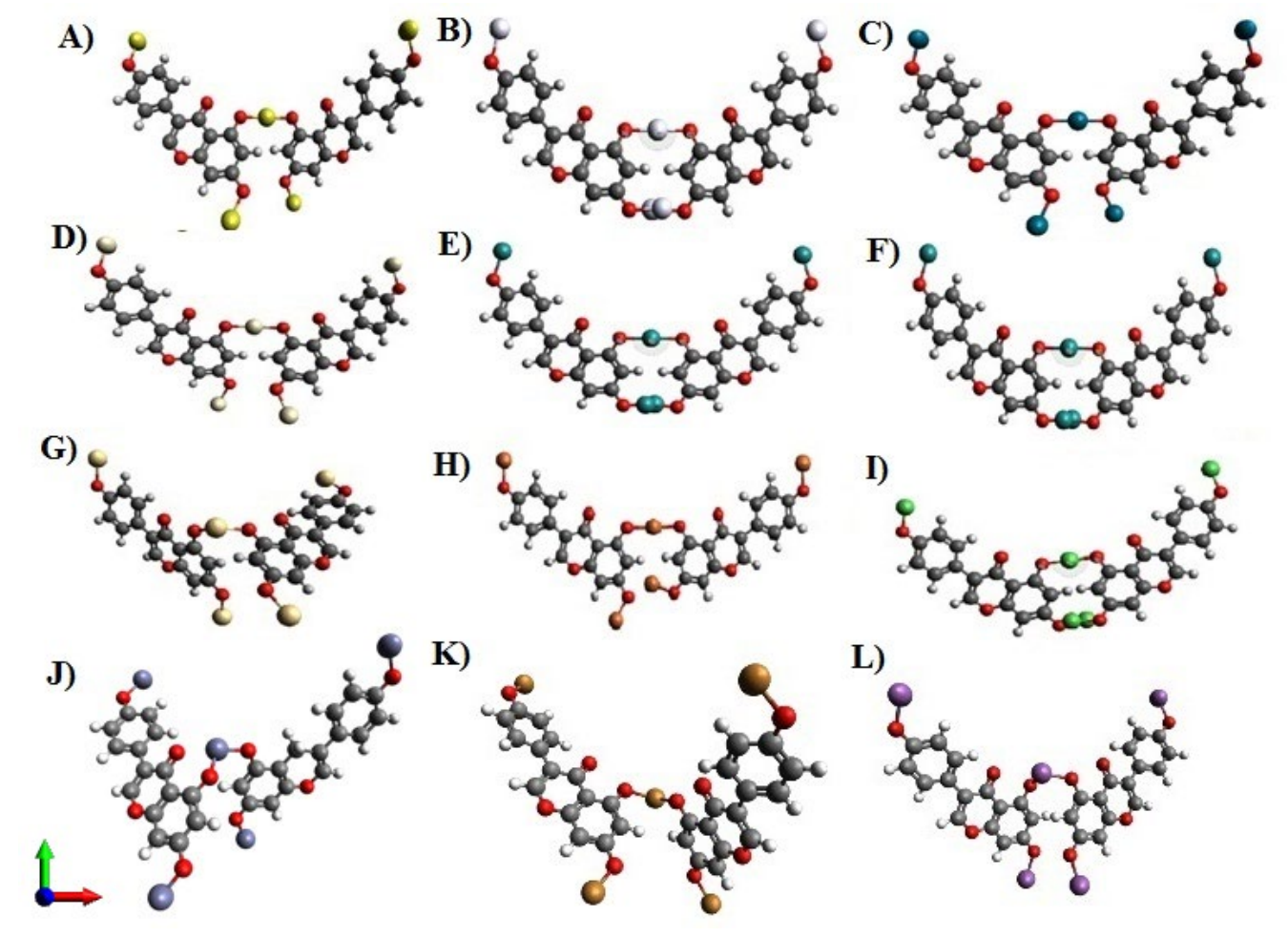

Figure 6 Nanocomposite model structure of metals with A) Gold (Au), B) Silver (Ag), C) Palladium (Pd), D) Platinum (Pt), E) Ruthenium (Ru), F) Rhodium, G) Cadmium (Cd), H) Iron (Fe), I) Nickel (Ni), J) Zinc (Zn), K) Copper (Cu), L) Antimony (Sb).

Table 2 List of energy levels for different metal-Genistein nanocomposite particles with bond angle and bond lengths.

\begin{tabular}{|c|c|c|c|c|c|}
\hline Metal & Compound name & $\begin{array}{l}\text { Energy } \\
\text { (KJ/Mol) }\end{array}$ & $\begin{array}{c}\text { Bond Angle } \\
\left(^{\circ}\right) \\
\mathrm{O}_{\mathrm{L}}-{\stackrel{\mathrm{Metal}}{-} \mathrm{O}_{\mathrm{R}}}\end{array}$ & \multicolumn{2}{|c|}{ Bond Length } \\
\hline Gold & $\mathrm{Au} \_\mathrm{Gy}$ & 457.117 & 178.5 & $1.862 \AA$ & $1.862 \AA$ \\
\hline Silver & Ag_Gy & 449.572 & $176.0^{\circ}$ & $1.969 \AA$ & $1.969 \AA$ \\
\hline Palladium & Pd_Gy & 449.202 & $89.8^{\circ}$ & $1.915 \AA$ & $1.915 \AA$ \\
\hline Platinum & Pt_Gy & 445.259 & $89.8^{\circ}$ & $1.957 \AA$ & $1.957 \AA$ \\
\hline Ruthenium & Ru_Gy & 445.691 & $174.1^{\circ}$ & $2.016 \AA$ & $2.016 \AA$ \\
\hline Rhodium & Rh_Gy & 448.646 & $175.0^{\circ}$ & $1.895 \AA$ & $1.895 \AA$ \\
\hline Cadmium & Cd_Gy & 430.015 & $109.0^{\circ}$ & $2.004 \AA$ & $2.004 \AA$ \\
\hline Iron & $\mathrm{Fe} \_\mathrm{Gy}$ & 452.493 & $174.3^{\circ}$ & $1.887 \AA$ & $1.887 \AA$ \\
\hline
\end{tabular}




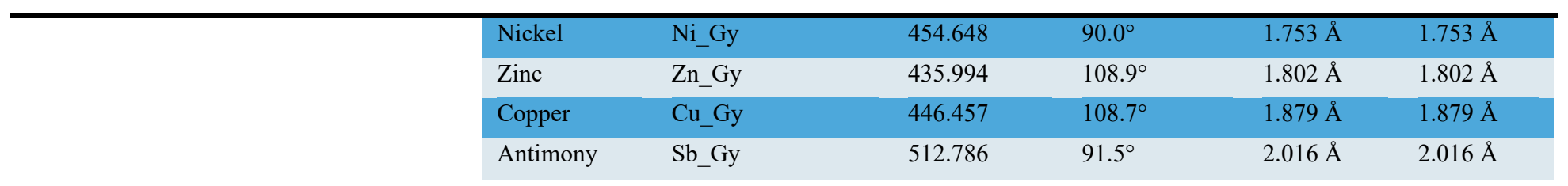

\section{CONCLUSION}

In glycitein molecules, the $\mathrm{OH}$ group present at 4' meta-position could be best suitable to be acting as a binding site for forming the bond amid two twin glycitein molecules.Whereas in case of genistein 5 Para position was found to be the appropriate one with the least energy-optimization against both 4' Meta and 7 ortho position - $\mathrm{OH}$ groups. The presence of - $\mathrm{CH} 3$ group in glycitin molecule may be the cause for this phenomenon. Supplementary to this on the addition of metals on the other sites excluding meta-position for glycitein and Para-position for genistein the energy was slowly depleting which could be encountered very well in the energy levels of two-drug molecules. In consideration of all, from the above observation cadmium metal was found to be forming the most stable nanocomposite structure with least energy in comparison to other selected metals, among them antimony being least stable in case of both the isoflavones.

\section{REFERENCES}

B. Duncan, C. Kim, and V. M. Rotello (2010), "Gold nanoparticle platforms as drug and biomacromolecule delivery systems," J. Control. Release Off. J. Control. Release Soc., vol. 148, no. 1, pp. 122-127, Nov, doi: 10.1016/j.jconrel.2010.06.004. Retrieved from https://doi.org/10.1016/j.jconrel.2010.06.004

C. A. Dos Santos et al. (2014), "Silver nanoparticles: therapeutic uses, toxicity, and safety issues," J. Pharm. Sci., vol. 103, no. 7, pp. 1931-1944, Jul, doi: 10.1002/jps.24001. Retrieved from https://doi.org/10.1002/jps.24001

C. I. C. Crucho and M. T. Barros (2017), "Polymeric nanoparticles: A study on the preparation variables and characterization methods," Mater. Sci. Eng. C Mater. Biol. Appl., vol. 80, pp. 771-784, Nov, doi: 10.1016/j.msec.2017.06.004. Retrieved from https://doi.org/10.1016/j.msec.2017.06.004

C. P. Adams, K. A. Walker, S. O. Obare, and K. M. Docherty (2014), "Size-Dependent Antimicrobial Effects of Novel Palladium Nanoparticles," PLoS ONE, vol. 9, no. 1, p. e85981, Jan., doi: 10.1371/journal.pone.0085981. Retrieved from https://doi.org/10.1371/journal.pone.0085981

C. S. Levin et al. (2009), "Magnetic-plasmonic core-shell nanoparticles," ACS Nano, vol. 3, no. 6, pp. 1379-1388, Jun., doi: 10.1021/nn900118a. Retrieved from https://doi.org/10.1021/nn900118a

C. Spagnuolo et al. (2015), "Genistein and cancer: current status, challenges, and future directions," Adv. Nutr. Bethesda Md, vol. 6, no. 4, pp. 408-419, Jul, doi: 10.3945/an.114.008052. Retrieved from https://doi.org/10.3945/an.114.008052

D. C. Vitale, C. Piazza, B. Melilli, F. Drago, and S. Salomone (2013), "Isoflavones: estrogenic activity, biological effect and bioavailability," Eur. J. Drug Metab. 
Pharmacokinet., vol. 38, no. 1, pp. 15-25, Mar, doi: 10.1007/s13318-0120112-y. Retrieved from https://doi.org/10.1007/s13318-012-0112-y

D. Guo et al. (2009), "Synergistic Effect of Functionalized Nickel Nanoparticles and Quercetin on Inhibition of the SMMC-7721 Cells Proliferation," Nanoscale Res. Lett., vol. 4, no. 12, pp. 1395-1402, Aug, doi: 10.1007/s11671- 0099411-x. Retrieved from https://doi.org/10.1007/s11671-009-9411-x

D. Hazra, D. Chatterjee, and R. Pal (2020), "Designing of Nanocomposite model structure using Gallic acid and Ellagic acid with four different metals," Int. J. Life Sci., vol. 8, no. 3, Art. no. 3, Sep. Retrieved from https://doi.org/10.21467/anr.3.1.40-45

G. Viauet al. (2003), "Ruthenium Nanoparticles: Size, Shape, and Self-Assemblies," Chem. Mater., vol. 15, no. 2, pp. 486-494, doi: 10.1021/cm0212109. Retrieved from https://doi.org/10.1021/cm0212109

H. K. K, N. Venkatesh, H. Bhowmik, and A. Kuila (2018), "Metallic Nanoparticle: A Review," Biomed. J. Sci. Tech. Res., vol. 4, no. 2, pp. 3765-3775, doi: 10.26717/BJSTR.2018.04.001011. Retrieved from https://doi.org/10.26717/BJSTR.2018.04.0001011

J. Kim, T. Shirasawa, and Y. Miyamoto (2010), "The effect of TAT conjugated platinum nanoparticles on lifespan in a nematode Caenorhabditis elegans model," Biomaterials, vol. 31, no. 22, pp. 5849-5854, Aug., doi: 10.1016/j.biomaterials.2010.03.077. Retrieved from https://doi.org/10.1016/j.biomaterials.2010.03.077

K. Shimoda and H. Hamada (2010), "Synthesis of beta-maltooligosaccharides of glycitein and daidzein and their anti-oxidant and anti-allergic activities," Mol. Basel Switz., vol. 15, no. 8, pp. 5153-5161, Jul., doi: 10.3390/molecules15085153. Retrieved from https://doi.org/10.3390/molecules15085153

L. Qi, H. Cölfen, and M. Antonietti (2001), "Synthesis and Characterization of CdS Nanoparticles Stabilized by Double-Hydrophilic Block Copolymers," Nano Lett., vol. 1, no. 2, pp. 61-65, doi: 10.1021/nl0055052. Retrieved from https://doi.org/10.1021/nl0055052

L. Xu, D. Liu, D. Chen, H. Liu, and J. Yang (2019), "Size and shape controlled synthesis of rhodium nanoparticles," Heliyon, vol. 5, no. 1, p. e01165, Jan., doi: 10.1016/j.heliyon.2019.e01165. Retrieved from https://doi.org/10.1016/j.heliyon.2019.e01165

M. D. Hanwell, D. E. Curtis, D. C. Lonie, T. Vandermeersch, E. Zurek, and G. R. Hutchison (2012), "Avogadro: an advanced semantic chemical editor, visualization, and analysis platform," J. Cheminformatics, vol. 4, no. 1, p. 17, Aug, doi: 10.1186/1758-2946-4-17. Retrieved from https://doi.org/10.1186/1758-2946-4-17

M. Pabich and M. Materska (2019), "Biological Effect of Soy Isoflavones in the Prevention of Civilization Diseases," Nutrients, vol. 11, no. 7, p. E1660, Jul, doi: $\quad 10.3390 /$ nu11071660. $\quad$ Retrieved from https://doi.org/10.3390/nu11071660

M. Thrane, P. V. Paulsen, M. W. Orcutt, and T. M. Krieger (2017), "Chapter 2 - Soy Protein: Impacts, Production, and Applications," in Sustainable Protein Sources, S. R. Nadathur, J. P. D. Wanasundara, and L. Scanlin, Eds. San Diego: Academic Press, pp. 23-45. doi: https://doi.org/10.1016/B978-0-12- 
802778-3.00002-0. Retrieved from https://doi.org/10.1016/B978-0-12802778-3.00002-0

P. Thangavel, A. Puga-Olguín, J. F. Rodríguez-Landa, and R. C. Zepeda (2019), "Genistein as Potential Therapeutic Candidate for Menopausal Symptoms and Other Related Diseases," Mol. Basel Switz., vol. 24, no. 21, p. E3892, Oct, doi: $\quad 10.3390 /$ molecules24213892. Retrieved from https://doi.org/10.3390/molecules24213892

R. Lu, Z. Zheng, Y. Yin, and Z. Jiang (2019), "Effect of Genistein on Cholesterol Metabolism-Related Genes in HepG2 Cell," J. Food Sci., vol. 84, no. 8, pp. 2330-2336, Aug, doi: 10.1111/1750-3841.14725. Retrieved from https://doi.org/10.1111/1750-3841.14725

S. A. Mahdy, Q. J. Raheed, and P. T. Kalaichelvan (2012), "Antimicrobial activity of zero-valent iron nanoparticles," Int. J. Mod. Eng. Res., vol. 2, no. 1, pp. 578581, doi: 10.1.1.416.6199.

S. Rojas et al. (2016), "Nanoscaled Zinc Pyrazolate Metal-Organic Frameworks as Drug-Delivery Systems," Inorg. Chem., vol. 55, no. 5, pp. 2650-2663, Mar, doi: 10.1021/acs.inorgchem.6b00045. Retrieved from https://doi.org/10.1021/acs.inorgchem.6b00045

S. Vrignaud, J.-P. Benoit, and P. Saulnier (2011), "Strategies for the nanoencapsulation of hydrophilic molecules in polymer-based nanoparticles," Biomaterials, vol. 32, no. 33, pp. 8593-8604, Nov, doi: 10.1016/j.biomaterials.2011.07.057. Retrieved from https://doi.org/10.1016/j.biomaterials.2011.07.057

S.-J. Suet al. (2005), "The novel targets for anti-angiogenesis of genistein on human cancer cells," Biochem. Pharmacol., vol. 69, no. 2, pp. 307-318, Jan, doi: 10.1016/j.bcp.2004.09.025. Retrieved from https://doi.org/10.1016/j.bcp.2004.09.025

T. Kruk, K. Szczepanowicz, J. Stefańska, R. P. Socha, and P. Warszyński (2015), "Synthesis and antimicrobial activity of monodisperse copper nanoparticles," Colloids Surf. B Biointerfaces, vol. 128, pp. 17-22, Apr, doi: 10.1016/j.colsurfb.2015.02.009. Retrieved from https://doi.org/10.1016/j.colsurfb.2015.02.009

W. H. De Jong and P. J. A. Borm (2008), "Drug delivery and nanoparticles:applications and hazards," Int. J. Nanomedicine, vol. 3, no. 2, pp. 133-149, doi: 10.2147/ijn.s596. Retrieved from https://doi.org/10.2147/IJN.S596

W. Yin, W. Chai, K. Wang, W. Ye, Y. Rui, and B. Tang (2019), "Facile synthesis of Sb nanoparticles anchored on reduced graphene oxides as excellent anode materials for lithium-ion batteries," J. Alloys Compd., vol. 797, pp. 12491257, doi: https://doi.org/10.1016/j.jallcom.2019.04.329. Retrieved from https://doi.org/10.1016/j.jallcom.2019.04.329 